\title{
Prasasti Tulang Er 198 Sanjaya
}

\author{
HB. Herry Santosa
}

Keywords: inscription, Tulang Er, Sanjaya year, Balitung, Daksa

\section{How to Cite:}

Santosa, H. H. Prasasti Tulang Er 198 Sanjaya. Berkala Arkeologi, 14(2), 186-190. https://doi.org/10.30883/jba.v14i2.720

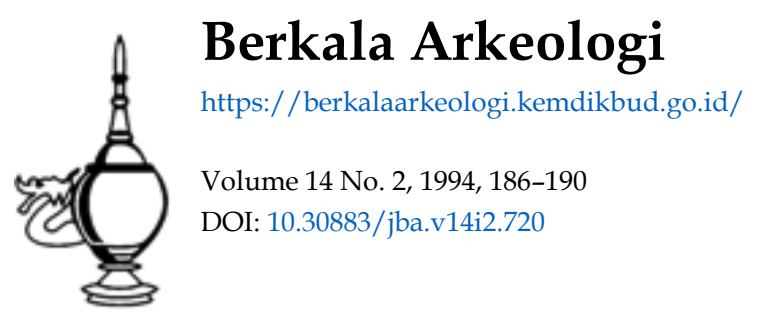

\section{c) (i) (2)}

This work is licensed under a Creative Commons Attribution-NonCommercial-ShareAlike 4.0 International License. 


\title{
PRASASTI TULANG ER 198 SANJAYA
}

\author{
HB. Herry Santosa \\ (Universitas Sanata Dharma)
}

I

Prasasti merupakan sumber sejarah tertuIIs yang banyak memberikan keterangan mengenal struktur birokrası, perekonomian, keadaan topografi, pemukiman dan juga menenai masalah masyarakat Indonsia Kuno beserta aktivitasnya. Berdasarkan data yang berhasil dikumpulkan, ratusan prasasti menggunakan tarikh Caka dan baru empat buah prasasti yang menggunakan tarikh Sanjaya. Keempat prasasti itu adalah Prasasti Taji Gunung. Prasasti Timbanan Wungkal, Prasasti Tihang dan Prasasti Tulang $\mathrm{Er}$

Pemakaian tarikh Sanjaya, sudah pernah dibıcarakan para sarjana, yang masing-masing berpegang pada hasil pembacaan angka tahun pada prasasti Taji Gunung dan Timbanan Wungkal. Brandes, yang membaca kedua prasasti untuk pertama kalinya, mengatakan bahwa angka tahun pada kedua prasasti itu harus dibaca 694 untuk prasasti Taji Gunung dan 693 pada prasasti Timbanan Wungkal. 'Berdasarkan hasil pembacaan tersebut Krom berpendapat bahwa permulaan tarikh Sanjaya sekitar tahun 217/216 $\mathrm{M}_{\text {, }}$ yaitu masa permulaan orang Hindu di Jawa. ${ }^{2} \mathrm{Se}$ dangkan Goris membaca angka tahun pada kedua prasasti itu sebagai $172 / 174$ dan 176 Sanjaya. Pendapat para sarjana tersebut terbantah setelah L. Ch. Damais berhasil membaca angka tahun kedua prasasti itu sebagai 194 dan 196 Sanjaya ${ }^{3}$ Pendapat L. Ch. Damais ini terbukti kebenarannya setelah diketemukan prasastı Tihang yang menggunakan dua tarikh yaitu 836 Caka dan 198 Sanjaya.

Satu lagi prasasti bertarikh Sanjaya, yaitu prasasti Tulang Er 198 Sanjaya. Prasasti yang sekarang disimpan di Museum Nasional inı be. lum banyak dibicarakar. Beberapa hal yang menarik dari prasasti ini adalah pemakalan gelar raja Daksa, Sambhanda / alasan dikeluarkannya prasasti, dan alasan digunakannya tarıkh Sanjaya
II

Prasasti Tulang Er 198 Sanjaya ditemukan di lembah Sungai Winongo Desa Sorok, Kabu paten Bantul, DIY Prasasti ini dipahatkan pada dua buah lempengan tembaga, yang pada saat diketemukan dalam kondisi yang penuh karat Lempengan I berukuran 39,3 x 20,5 CM dan ditulis pada kedua sisinya. Sisi depan terdiri dari 14 baris dan sisibelakang memuat 13 baris. Lempengan kedua berukuran $39,2 \times 21 \mathrm{Cm}$, dan ditulis pada satu sisi yang memuat 13 baris. Masing-masing lempengan tidak bernomor, tetap। bagian penutup terdapat pada lempeng kedua sehingga dapat diduga bahwa parasasti inı merupakan prasastı yang lengkap. Berdasarkan paleografisnya, menunjukkan bahwa bentuk tulisan yang digunakan sama dengan prasasti-prasast yang berasal dari abad $X$

Prasasti Tulang Er dikeluarkan pada tanggal sepuluh bulan Posya tahun 198 Sanjaya. Prasasti ini memuat keterangan tentang pemberian anugerah oleh Räja Daksa kepada para räma yang mengurus kabikuan di Tulang Er. Adapun yang menjadi alasannya (Sambhanda) adalah para räma telah menyediakan air pemandian bagı räja Daksa ketika singgah di Bulussan sehabıs melakukan perjalanan dari kota. Selanjutnya prasasti ini menyebut daftar nama-nama pejabat yang menerima persembahan dan daftar namanama pejabat yang terlibat dalam upacara pernberian anugerah sima tersebut. Bagian akhır prasasti ini berisi kutukan yang ditujukan kepada semua orang yang berani mengusik isı atau ketentuan yang tetulis dalam prasasti. Di sampıng berisi kutukan, bagian akhir Juga berisi harapan yang ditujukan buat räja, semoga kemurahan hatinya itu mendapat pahala, umur panjang dan yang paling penting adalah demi tetap tegaknya Sang Hyang Dharmma.

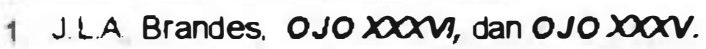

2 N.J. Krom. Hindoe Javaansche Geschie-denis, 's Gravenhage Martinus Nijhoff, 1931, hlm. 191.

3. L Ch. Damais, "Etudes d'Epigraphie Indonesiene N., Discussion de la date des Insçriptions", BEFEO X2W. 1955, h/m. $42-63$.

4 Keterangan ini diperoleh dan Tingangga. karyawan Museum nasıonal Jakarta. yang membaca prasast ini untuk yang pertama kali

5. Kemungkınan ada aiasan laınnya karena kata berikutiya aus sehingga tidak tertaca 
III

Membicarakan Prasasti Tulang Er 198 Sanjaya pada khususnya, atau prasasti bertarikh Sanjaya pada umumnya, tidak terlepas dengan tokoh räja Daksa, karena pada masa pemerintahannyalah prasasti-prasasti ini dikeluarkan. Bicara mengenai pribadi räja Daksa, cukup menarik. terutama nama gelar yang disandangnya. Dari beberapa prasasti yang berasal dari jaman Balitung, nama lengkap Daksa adalah Rakryan Mahamantri i Hino Cri Daksottama Bahubajrapratipaksaksaya Wisnu-murti. ${ }^{6}$ Nama ini bertambah panjang setelah Daksa menjabat sebagai räja yaitu Çri Mahäräja Rakai Hino Çri Daksottama Bahubajrapratı-paksaksaya Çri Mahottunggawijaya Wisnumurti. Nama ini sebenarnya sudah tertulis dalam prasasti Timbanan Wungkal 196 Sanjaya, yang merupakan prasasti pertama yang menyebut Daksa sebagai Çri Mahäräja, hanya tanpa kata Wisnumuiti. Pada kenyataannya tidak semua prasasti yang dikeluarkan räja Daksa menggunakan gelar yang demikian, bahkan ada yang menyebut tanpa gelar sama sekali seperti yang tertulis dalam prasasti Wintang Mas $841 \mathrm{C}$.

Pemakain nama gelar yang digunakan seorang raja, selain sebagai tanda (identitas diri), biasanya juga mempunyai maksud-maksud tertentu. Ada nama gelar yang dipakai untuk menunjukkan nama daerah (lungguh), hubungan kekerabatan dan ada pula yang dipakai untuk menunjukkan suatu kepercayaan yang dianutnya (dewa yang dipuja). Gelar kerakaian (yang didahului dengan rakai) biasanya menunjukkan nama daerah, baik daerah lungguh maupun daerah penobatan. Nama gelar yang menunjukkan adanya hubungan kekerabatan biasanya dengan mencantumkan nama räja pertama darı suatu räja kula yang dianggap sebagai pendiri dinasti. Sebagaı contoh adalah räja-räja Majapahit di dalam menunjukkan bahwa dirinya keturunan atau anggota wangsa Räjasa, selalu mencantumkan kata Rajasa di dalam nama gelarnya. Demikian pula keturunan pu Sindok yang selalu mencantumkan kata ıçana dı dalam nama gelarnya. Sedangkan pemakaian nama gelar yang bertujuan untuk menunjukkan kepercayaan yang dianut di antaranya

6. Nama gelar dengan tambahan Wisnumurt hanya terdapat pada prasast Wanua Tengah III 830 Caka, dan nama ini juga hanya tercantum dalam prasasti Tulang Er 198 Sanjaya selama Daksa monjabat sebagas räja.

7. Di dalam prasast Wintang Mas 841 Caka. nama räja Daksa tertus Çri Mahääja Rakai Hino pu Daksa. dengan penyebutan nama dewa di belakang nama gelar penobatan, seperti Wisnumurti, Rudramurti, dan Narasınghamurti. Sehubungan dengan hal tersebut, nama gelar räja Daksa seperti yang tercantum dalam prasasti Tulang Er 198 Sanjaya, selain sebagai identitas diri juga memiliki maksud-maksud tertentu. Nama Rakai Hino, menunjukkan bahwa Daksa memang memiliki daerah lungguh di Hino atau setidak-tidaknya Daksa pernah dinobatkan di daerah Hino. Sebutan Cri Daksottama merupakan nama yang dipakainya sejak lahir (garbhanama). Sedangkan yang menjadi masalah disini adalah nama Bahubajrapratipaksaksaya. Tambahan bahu-bajrapratipaksaksaya, merupakan nama gelar yang mungkin sekali disandangnya sejak menjabat sebagai rakai Hino pada masa pemerintahan Balitung Kemungkinan lain adalah nama ini merupakan kepanjangan dari Garbhanamanya

Pada waktu Daksa menjabat sebagaı räja, nama gelarnya semakin panjang dengan tambahan nama Çri Mahottunggawijaya, seperti tampak dalam prasasti Timbanan Wungkal 196 Sanjaya, merupakan prasasti pertama yang menyebut Daksa sebagai Çri Mahäräja. Gelar penobatan ini cukup menarik karena hanya disebut dalam tiga buah prasasti yang dikeluarkan berturut-turut di awal masa pemerintahannya. Tiga prasasti itu adalah Prasasti Timbanan Wungkal 196 Sanjaya, Prasasti Tihang 198 Sanjaya dan Prasastı Tulang Er 198 Sanjaya. Adanya unsur tungga di dalam gelar penobatan ini mengingat-kan pada nama räja-räja dari dinasti Syailendra Kata tungga sendiri berarti ujung atau puncak, yang dalam dinasti Syailendra dimaksudkan un-tuk menghormati dewa atau penguasa gunung yang dianggap sebagai cikal bakal dinasti terse-but Ada tidaknya hubungan antara Daksa de-ngan keluarga Syailendra belum dapat diketahuı karena mulai dari masa pemerintahan Balitung dan masa-masa berikutnya hampir semuanya menggunakan gelar dengan unsur tungga

Pemakaian geiar penobatan Çrı Mahottunggawijaya oleh Çri Daksottama ını dapat dıpahami karena secara harafiah nama gelar itu mempunyai arti "sebuah kemenangan yang besar". Hal inı dapat dimengerti bila dihubungkan dengan tergesernya hak Cri Daksottama oleh Balitung untuk duduk di atas takhta keräjaan Mataram. Berdasarkan adanya penyimpangan di dalam sistem pergantian takhta itulah tampaknya yang mendorong Cri Daksottama menggunakan nama gelar Çri Mahottunggawijaya

Di muka telah disebutkan bahwa penye. butan tokoh dewa di dalam nama gelar seorang räja dimaksudkan untuk menunjukkan bahwa $d_{\text {:- }}$ rinya merupakan penjelmaan atau setıdak-tıdaknya pemuja dewa yang bersangkutan Demikıan 
pula dengan penyebutan tokoh dewa Wisnu di belakang nama gelar räja Daksa. Di dalam Prasasti Tulang Er 198 Sanjaya, räja Daksa disebut dengan nama lengkap Çri Mahäräja Rake Hino Çri Daksottama Bahu-bajrapratipaksaksaya Çri Mahottunggawijaya Wisnumurti. Tambahan kata Wisnumurti ini sebenarnya sudah ada sejak Daksa menjabat sebagai Rakryan Mahamantri i Hino, seperti tertulis dalam prasasti Wanua Tengah III 830 C. Suatu hal yang tidak biasa terjadi dalam suatu sistem pemerintahan ada seorang pejabat pemerintahan yang memuja dewa yang berbeda dengan yang dilakukan räjanya. Hal ini menunjukkan adanya pandangan yang berbeda antara räja Balitung dengan Daksa sebagai pejabat pemerintahan di bawahnya, sekaligus menunjukkan bahwa selama pemerintahan räja Balitung, Daksa selalu berusaha untuk memperoleh kembali haknya untuk dapat duduk di atas takhta keräjaan Mataram. Di dalam prasasti Wanua Tengah III 830 C juga disebutkan bahwa saran pemuka agama dan pejabat pemerintahan untuk merubah status sawah di Wanua Tengah disampaikan melalui Daksa. Adanya hubungan yang dekat antara Daksa dengan pejabat pemerintahan maupun pemuka agama ini menunjukkan bahwa pemakaian gelar Wisnumurti oleh Daksa mendapat dukungan serta restu dari para pejabat maupun pemuka agama.

Tindakan Daksa dalam menggunakan gelar Wisnumurti, baik ketika menjabat rakryan Mahamantri I Hino maupun ketika menjadi räja, apa bila dikaitkan dengan konsep kosmologis, yang oleh Shçrieke disebut dengan konsep kaliyuga, ada kesesuaiannya. Sebenarnya konsep ini dipakai untuk membenarkan fakta sejarah tentang digulingkannya seorang Mahäräja oleh räja bawahannya, sebab sebagai dewa di dunia, kedudukan seorang Mahäräja tidak dapat diganggu gugat. Oleh karenanya, apabila terjadi penggulingan seorang Mahäräja, baik oleh räja bawahan maupun oleh räja dari mandala lain, kejadian ını disebut dengan pralaya, dan tokoh yang menyelamatkan /membangun kembali keräjaan dikatakan sebagai penjelmaan Wisnu. Oleh kare-

8. Keterangan ini terdapat pada lempeng $\|$ baris 7 dan 8 yang menyebutkan

7 ri kanang kulam i rikan pamatipi bhatara swami mahulun i lekan

8. i rakyan mahamantri i hino çri daksottama bahubajrapratipaksaksaya. kumonakan ikanan sawah bihara i pikatan inwahakna yathanyan mapageha palungguh çri mahäräja

9. B. Shçrieke "Ruler and Realm in Early Java", Indonesian Sociological Studies, 8 . Bandung The Hague. 1957, him. 77 - 78. na tujuannya sama yaitu untuk membangun kembali keräjaan dari sistem pergantian takhta maupun sistem pemerintahan yang tidak berjalan sebagaimana mestinya, maka Daksa menggunakan Wisnumurti di dalam nama gelarnya agar dianggap sebagai penyelamat keräjaan

Pada bagian terdahulu, telah disinggung bahwa isi prasasti Tulang Er adalah memperingati pemberian anugerah sima kepada para rama yang mengurusi kabikuan Tulang Er karena mereka telah menyediakan air pemandian bagi Çri Daksottama ketika melakukan perjalanan darı kota. Perjalanan dari kota ini tentunya bukan hanya perjalanan biasa, mengingat perjalanan ını dilaksanakan di awal pemerintahannya, lebih-lebih bila dikaitkan dengan pemberian anugerah kepada pejabat-pejabat daerah. Penyediaan aır pemandian bagi seorang räja, tentunya bukan suatu hal yang istimewa, bahkan merupakan kewajiban bagi warga masyarakat dalam menghormati räjanya. Oleh karena itu, pemberian anugerah ini tentunya untuk menarik sımpati masyarakat agar kedudukannya sebagaı räja dapat diterima dan diakui oleh semua warganya. Dengan demikian, dapat dikatakan bahwa perjalanan itu memiliki makna politik, mengingat penguasa yang memerintah sebelumnya, yaitu $\mathrm{Ba}$ litung merupakan seorang räja yang cukup dlsegani. Berdasarkan beberapa prasasti, dapat diketahui bahwa Balitung adalah seorang penguasa Jawa yang pertama kali menaruh perhatian terhadap wilayah Jawa Tengah dan Jawa Timur bahkan dari salah satu prasasti yang dikeluarkannya diduga pernah mengadakan penyerangan ke Bali. Dari bukti-bukti ini, wajar bila sebagian masyarakat masih menaruh rasa hormat dan mengagungkan nama Balitung.

Membicarakan prasasti Tulang Er 198 Sanjaya, tidak dapat dilepaskan dengan prasastı bertarikh Sanjaya lainnya, lebih-lebih bila membicarakan latar belakang digunakannya tarıkh tersebut. Dari empat buah prasasti, tıga di antaranya menyebut Daksa sebagai Cri Maharaja dan dikeluarkan di awal pemerintahannya. Tiga buah prasasti yang dimaksud adalah prasasti Timbanan Wungkal, Prasasti Tihang dan Prasasti Tulang Er. Pengabadian Sanjaya ke dalam tarikh ini pada kenyataannya memiliki tujuan polıtis yaitu untuk memperoleh kembali hak Daksa untuk dapat duduk di atas takhta keräjaan Mataram

Berdasarkan perhitungan seperti yang d. lukiskan dalam prasasti Tihang, dapat diketahuı bahwa permulaan tahun Sanjaya dimulaı pada tahun 638 Ç. Tahun ini tentunya merupakan tahun yang memiliki arti penting dalam kehıdupan Sanjaya. Mungkin sekali tahun satu Sanjaya merupakan tahun kelahiran Sanjaya, yang 16 tahun kemudian duduk di atas takhta keräjaan yang di- 
tandal dengan pendirian lingga atas bukit Sthirangga, seperti tampak dalam prasasti Canggal 654 C. Pengabadian Sanjaya ke dalam tarikh yang dilakukan Daksa dalam rangka melegitimasi dirinya, selain memiliki arti sebagai lambang identitas, juga untuk menarik simpati masyarakat. Sebagai sarana legitimasi, dilakukan Daksa dalam rangka memperoleh kembali haknya untuk duduk di atas takhta keräjaan Sebagai lambang identitas, tampak bahwa prasasti-prasasti bertarikh Sanjaya ini hanya dikeluarkan pada masa pemerintahan Daksa saja Sedangkan di dalam menarik simpati masyarakat, dilakukan Daksa karena menyadari bahwa penguasa sebelumnya, yaitu räja Daksa, adalah seorang räja yang memiliki nama besar dan keberadaannya telah diakui oleh masyarakat Pada kenyataannya, alasan dan tujuan pemakaian tarikh Sanjaya ini saling kait mengkait dan tidak dapat dipisah-pisahkan

\section{IV}

Prasasti Tulang Er 198 Sanjaya adalah prasasti keempat yang menggunakan tarikh Sanjaya Prasasti inı pada dasarnya tidak merubah teori maupun rekonstruksi sejarah yang sudah ada. Akan tetapi keberadaan prasasti inı pada kenyataannya dapat melengkapi penulisan sejarah yang sudah ada. Tarikh Sanjaya, tidak lagı hanya sebagai pelengkap tarikh yang pernah digunakan dı Indonesıa, tetapı juga merupakan ouktı bahwa pada masa pemerintahan Balitung Daksa pernah terjadi konflik di kalangan istana Jalam rangka memperebutkan takhta keräjaan Dengan kata lain, membicarakan prasastı bertarikh Sanjaya, tıdak lagi hanya berkisar pada angka tahunnya saja, tetapı banyak masalah yang dapat diungkap dari tarikh tersebut. Salah satu masalah yang dapat terungkap dari prasastıprasastı itu antara lain kondisı dan situasi politik pada masa pemerintahan Balitung. Penelitian lebıh mendalam terhadap prasasti-prasastı ını diharapkan dapat mengungkap aspek lain sejarah indonesia kuno pada umumnya dan masa pemerintahan Daksa-Balitung pada khususnya

\section{KEPUSTAKAAN}

Boecharı, 1963. "A Preliminary Note on the Study of the Old-Javanese Civil Administration", M.J.S.I. I, No.2, hlm. 122 - 133.

1965, "Epigraphy and Indonesian Historiography", dalam Soedjatmoko et al, An introduction to indonesian His- toriography, ithaca: Cornell University Press, hlm. 47 - 73

1983, Prasasti Wanua Tengah III 830

Caka, Jakarta, tidak diterbitkan

Brandes JLA., 1913., Oud Javaansche Oorkonden. Nagelaten Transçripties van Wijlen Dr. JLA. Brandes, uit gegeven door Dr. N.J. Krom, VBG LX.

Casparis, J.G.de,1975, Indonesian Paleography; A History of Writting in Indonesia from the beginning to Century $A D$ 1500, Leiden/Kohln: E.J. Brill

Damaıs, L.Ch., 1951., "Etudes d'Epigraphie Indonesienne II, la Date des Insçriptions en ere Sanjaya" BEFEO XLV, hlm. 42 - 63

1955. "Etudes d'Epigraphie Indonesienne IV. Discussion de la Date des insçriptions", BEFEO XLVII

Heine Geldern, R. von., 1972, Konsepsi tentang Negara dan Kedudukan Radja di Asia Tenggara, ter . Deliar Noer, Jakarta: Keguruan dan limu Pendidikan

Kusen, 1983, Transkripsi Sementara Prasasu Wanua Tengah III 830 Caka, t. diterbitkan

Sarkar, HB , 1959. The Stone Insçriptions of Kıng Sanjaya (Canggal insçriltions) 654 Ģ. Journal of the Asiatic Society !, . No. 2

Schrieke, B., 1957, Ruler and Realm in Early Java, Indonesian Sociological Studies II, Bandung : The Hague

Sukarto KAtmodjo, MM.,1979., Sinktur Masyarakat Jawa Kuno pada jaman Mataram Hindu dan Majapahic, Yogyakarta. Pusat Penelitian \& Studı Pedesaan \& Kawasan UGM

Trıgangga, 1987. Prasasti Räja Daksa 198 San jaya Romantika Arkeologsa, jakaita Fak. Sastra UI. nim. 25-33.

Wibowo, A.S 1976, Balitung Pernah menyerang Bali, Bulletin Yaperna No 11 Th. Ill, hlm. $64 \cdot 76$ 


\section{Lampiran}

\section{Transkripsi prasasti Tulang Er 198 Sanjaya.}

la

1. II swasthá çri sañjaya warsātita 198 posya măsa tithi ekadaçi (...)

2. naksatra. dahana dewata. çuklayoga. irika di-wasa ni anugraha çri mahărajja rokai hino çri dakso

3 Hama bahubajrapratipaksaksaya çri mahottunggawijaya wișnumurt tumurun (. . . ) i ka

4. bikwan i tulan er wat tilimpik sambandhanya matangnyan inanugrahan de çri mahărăja (. . .) çn mahā

5. răja mare budusan humus ning kuta alih mahadangakan ta ikanang rāma muai padyus muang (. . .)

6. n. mangkana gawainya sapangidul çri mā-hārāja. tinakwanan pu ayari kinawanknanyan tan hana (. . .)

7. mametta sawah kawnangnaknamyan pahadańngakan unai padyus ri pangidul çri mahărăja tan pama (

8. nya kayanya alih wij andehanya kunang kaya tampah 2 ya kawnangaknanya lingnya dadiya sinanmata de çri mahärāja (...)

9. nkanang samwahnya mangandeha kaya prana 2 mangaseakan nikanang räma pageh-pageh saluir ni mangandeha (

10 çri mahā rāja

11 nya pgeli-pageth i sang (. . . ) wanua pirak unḍi ka 1 tilimpik rikang kala pu natula anak wanua । karämas

$12(\ldots)$

12 ( In muang mangaseaknanya pagel,-pageh : samgat baleng dan acaryya pamiddhana-cupata

13 humah (....) pu gabwira (. ) ning pu burl ka-pua winaih pirak undi dha 1 sowang sowang (..)

14 ( i pirak ka 2 wdihan yü 1 (. ) pu Imah jari inasean dhā 1 wdihan yũ (...)

Ib

1. sang tiru mnatì dhā 1 wdihan yơ 1 tuhan ri tilimpik nkanang diwasa juru kanayakan samgat mungkalantan. Juru ni la

2. mpuran sang bama anak wanua imrik wrik watěk wrik wrik juru ning wadwa rare sang kusuma anak wanua I karåmas wa

3. těk kanginnangin. Jurunirg kalula sang nagara anak wanua I yamwilan watik pakuwangi. jununing mandakat dyah da

4. mok anak wanua i hayan sang ma i tang-kiamwok, atanda sang lituh anak wanua i karämas watek kanginnangin, abalu

5. n sang dmung anak wanua i wuga waték tilimpik. parujar sang patuñjungan anak wanua i patihatton. sima kalang ri daha

6. 11. amasaningakan sang suthi anak wanua i tasikkanak watěk tilimpik inasean pagèh pagěh pirak $u$

7 ndi thā 5 knawetran // sanganungu inangsean ma 8 kuluwar ikang diwasa sang tamk muang kundiwal muang sang jangga
8. sang kulup anak wanua i wirtnya watěk tilimpik juru (. . ) pu kakumpang anak wanua i wimnya watěk tilimpik

9. tutugan tanda kapua winaih pirak undi dhā 1 sowang sowang răma tumarimanugraha çri mahărăja. tưha kalang pu

10.te răma ni daga. gusti 6 pu galunah răma ni basura pu gurun räma ni kpu. pu nabandra răma ni tanah. pu tula răma ni dewa.

11. pu haryya răma ni amok. pu dyu răma ni cadi "l tuha wanua pu landhayan kaks wala. pu sunung răma nı mantal pu

12.kopos răma ni prasan. pu garagap kaki dhawa. pu basita răma ni rañga. pu walan răma n gama / winkas 2 pu pI

13. nuw răma ni karawal. pulegendhe (. . . ) râma m nuki/ (. . .)m 2(. . ) dya râma ni parujahthan pu wu răma n।

II.

1. mada

2. pu manu răma ni longa (. . ). tuhalas 2 pu unju răma ni (. . ) răma ji. añañam 2 pu saha

3. ra răma ni amita pu bite răma ni dharita. parujar 2 pu dman răma ni nura pu dewara räma ni watun tuha wérh 6 pu ba

4. kor răma ni (. . ) bama pu wina răma nitanıbak. pu suryya răma ni laksita. pu mi (. . ) răma ni (. . ) pu tate (...)

5. bana răma ni ba(. . ) răma marat pu padma răma nı butik. pu ratu rảma ni mandhata pu (. . ) răma nı samya ( ... )

6. răma ni kĕdér pu unlt (. . )i pu lamakan răma nı duwat pu saha(. . .)

7. răma ni bunkah muwah tuha ni (. . . ) pu uñjo răma ni i ..)

8. pu sumpal răma ni kưup. pu pingul răma nı grasi. pu wait răma ni wayuh. pu kongon răma ni puji. dewo karmma (...)

9. (. . ) ine. samangkana kwain nıkanang răma tumanma anugraha çri mahärāja. kunang yan hana umulalihulah ikeng prasa

10.st ri dlaha ning dlaha upradawa ya yapwan pjan muliha ring mahapataka klan ning kawah de sang hyang yamabala yan tan

11.hana ta ya rikeng yawacwipa saluir ning mahasangsara kirannya tan pada muang sajana ta tan siddha karyya tan pa

12.nguha phala ni pamritinya matangnyan an kayatnakna soni ningke prasasti makaphala kajayadirghayusan

13.i çi mahăraja muang huripa sang hyang dhar-mma mañurat prasasti citralekha ri konang sayowana 